\title{
FACTORES DETERMINANTES DE LA INVERSIÓN EXTRANJERA DIRECTA EN ALGUNOS PAÍSES DE LATINOAMÉRICA MOGROVEJO, Jesús A.
}

\section{Resumen}

En esta investigación se analizan los factores determinantes de la inversión extranjera directa (IED) en América Latina, con especial referencia a la Comunidad Andina, el MERCOSUR - Chile y el bloque de países Centroamericanos - Caribeños y México. Se realiza un estudio econométrico cuyo resultados corroboran que la IED en los diecinueve países latinoamericanos estudiados son determinados, principalmente, por el tamaño de mercado, la apertura comercial y el riesgo país, además de sucesos atípicos relacionados a privatizaciones y a grandes emprendimientos empresariales privados. También se analizan las características que explican la situación de los países menos avanzados en este sentido.

Palabras clave: IED, Inversión extranjera, Latinoamérica.

\section{Abstract}

This study analyzes the main factors which explain Foreign Direct Investgment (FDI) in Latin America, with special reference to the Andean Community, Mercosur-Chile and the block of Central American-Caribbean countries and Mexico. We present an econometric analysis which shows that FDI in the nineteen Latin American countries studied depends basically on the market size, trade openness and country risk, besides some particular circumstances related with privatizations and a few big investments. We also analyze the main features that explain the situation of the least advanced countries in this regard.

JEL classification: C51, F21, F23, O54

Keywords: FDI, Foreign Investment, Latin America.

* Jesús A. Mogrovejo, economista boliviano, Master de Economía Sectorial Internacional y estudiante del Doctorado de Economía Aplicada en la Universidad de Santiago de Compostela. E-mail: je_mogrovejo@yahoo.es 


\section{Introducción}

A partir de la década de los años noventa, América Latina ha renovado el interés mundial para ocupar una posición relevante en la recepción de flujos internacionales de inversión. Flujos que se concentraron en países de la región por presentar los mejores performances comparativos para atraer la Inversión Extranjera Directa (IED).

La IED sólo representa una acción dentro de las variadas maniobras de expansión mundial de algunos emprendimientos empresariales capaces de localizarse fuera de sus economías de origen. Acciones que repercuten y se hacen imprescindibles en aquellos países que carecen de recursos financieros y tecnológicos. En general, los países receptores de IED esperan que esta genere: la creación de empleos, el contacto con nuevas ideas, tecnologías y prácticas de trabajo, mayores recaudaciones impositivas, fomento y creación de tejidos industriales, etc. Por ende, todos los beneficios que pueden ser encausados para mejorar el bienestar de sus sociedades. Al margen de los efectos positivos de la IED, en sí misma posee una enorme trascendencia, porque a diferencia de los movimientos financieros de capital, la firma que decide invertir en el extranjero adopta mayores compromisos con los países huéspedes de dicha inversión, frente a otras alternativas de internacionalización de sus operaciones ${ }^{1}$. De la manera planteada, es posible diferenciar dos núcleos explicativos: la firma extranjera y la economía que es objeto de la niversión. El presente artículo sólo pretende aclarar los motivos generales que permiten a las empresas inversoras localizarse en diecinueve países latinoamericanos, para conocer las causas que determinan que los inversores externos efectúen sus actividades en un país determinado y no en otro.

Esta investigación se sustenta en la hipótesis general de que existen factores generales determinantes de la IED en los países estudiados ${ }^{2}$, los cuales se hacen más específicos cuando se limitan a convenios de complementariedad económica como: la Comunidad Andina, el

\footnotetext{
${ }^{1}$ Exportaciones, licencias, concesiones Buckley y Casson (1981).

${ }^{2}$ Que serán descritos más adelante
} 
MERCOSUR - Chile y el bloque de países Centroamericanos Caribeños y México. En cuanto al orden del presente trabajo, este se divide en cinco secciones. Luego de esta introducción, se presenta una breve revisión teórica de los principales fundamentos de la IED. En el punto 3 se aborda un análisis descriptivo de la IED, en el que se explica su evolución de una manera global y sectorializada. En el punto 4 se efectúan los modelos econométricos. Por último, en el punto 5 se consigna las conclusiones más importantes del presente estudio.

\section{Fundamentos Teóricos}

Los motivos que viabilizan la inversión extranjera y sus consecuencias han sido objeto de construcción de diversas teorías, sin embargo, estas se encuentran delimitadas por las características de las industrias y sus formas de relacionamiento interno como externo. Como todas las ciencias sociales, los investigadores que han procurado un método científico para analizar la IED, se han limitado a la inducción a partir de casos observados. Por lo tanto, sin la posibilidad de una experimentación controlada, tenemos que basarnos en la interpretación de la evidencia, lo que supone que no es posible obtener una respuesta exacta. Es así que la teoría con un aval científico medianamente reconocida, mantiene dos tendencias reveladas: la primera es que se cierne sobre la industria manufacturera y la segunda proviene de realidades de los países industrializados.

De acuerdo a las estadísticas disponibles por la United Nations Conference Trade and Development (UNCTAD), cerca del $90 \%$ de los flujos de IED son realizadas por firmas con características oligopólicas, puesto que las mismas detentan grandes segmentos de mercado, por poseer fortaleza financiera y todas las ventajas que generan la propiedad de patentes y tecnología. Esta situación ya habría sido identificada por Hymer (1968) y Dickenson (1967), aduciendo que en los mercados mundiales en la primera mitad del siglo XX ya se encontraban en una situación monopolística. Otros autores como Bergstrand, (1985), Krugman (1992) y Markusen (1995) han insistido que las restricciones del libre tránsito de bienes y factores de producción, la cercanía o lejanía a los centros económicos 
mundiales y las diferencias culturales también formarían parte de los determinantes de la IED.

Por consiguiente, el conjunto de explicaciones de la IED podría contener un vasto alcance analítico. Esta situación ocasiona que se carezca de una metodología apropiada. De este modo Dunning (1977) propone un marco analítico que explicita las condiciones y mecanismos necesarios para que una firma pueda localizarse en una economía extranjera. A esta metodología la ha denominado como "Enfoque Ecléctico", el cual se sustenta en tres elementos: Ventajas de propiedad, Ventajas de localización; y la Internalización de las ventajas de propiedad.

La secuencia explicativa es la siguiente: para que se produzca la IED, la firma propietaria de ventajas que le hacen competitiva en los mercados donde se desempeña, internalizará sus ventajas para tomar el control de sus actividades en el extranjero; si las condiciones de ubicación y localización de las economías a donde se dirige son lo suficientemente atractivas para generar potenciales beneficios. Es así que las empresas que deseen invertir en otras economías deberán evaluar todos los aspectos de las potenciales economías huéspedes. Tomarán en cuenta los tamaños de mercado ${ }^{3}$, la dotación de factores de producción ${ }^{4}$, particularidades de los sistemas institucionales ${ }^{5}$, la infraestructura $^{6}$ y la estabilidad macroeconómica ${ }^{7}$.

Sobre la base de este contexto, Dunning (1994) clasifica a la IED, de acuerdo a su motivación de localización, en cuatro grandes elementos: 1. Búsqueda de recursos naturales, 2. Búsqueda de mercados, 3. Búsqueda de eficiencia, 4. Búsqueda de activos estratégicos.

\footnotetext{
3 Para calibrar las posibilidades de consumo interno, así como la generación de economías de escala.

${ }^{4}$ Recursos humanos calificados, know how tecnológico, oportunidades de financiamientos más bajos, etc

5 Grados de intervención de los gobiernos en las economías, estabilidad política, respeto de los derechos de propiedad, etc.

${ }^{6}$ Carreteras, ferrocarriles, dotaciones de actividades aeroportuarias.

${ }^{7}$ Inflación, volatilidad del tipo de cambio y tasas de interés.
} 
Cierto es que estos objetivos no son excluyentes entre sí, también es claro que los mismos se encuentran en función al tipo de industrias. Las dos primeras modalidades aluden, en general, a los objetivos de la inversión inicial de una Empresa Transnacional (ET) que no precisan mayor explicación, en tanto las dos restantes corresponden, básicamente, a modos de expansión de una firma ya establecida.

Las inversiones para la búsqueda de mercados son seguidas con frecuencia de inversiones basadas en la búsqueda de eficiencia, en las cuales se trata racionalizar la producción para explotar economías de especialización, a través de la IED en países dotados de factores menos caros con relación a su productividad. Tanto los procesos de integración regional como la reducción de los costos de transporte y los avances en las telecomunicaciones favorecen este tipo de estrategias, ya que frecuentemente se materializan a través de procesos de complementación, tanto comercial como productiva, de las operaciones filiales - corporación transnacional.

El objetivo central de las estrategias de búsqueda de activos estratégicos es adquirir recursos y capacidades que pueden ayudar a la firma inversora a mantener y acrecentar sus capacidades competitivas en los mercados regionales o globales, como la búsqueda de tecnologías y conocimientos específicos: estructuras organizacionales, acceso a canales de distribución, marketing destinado a diferentes culturas, etc. En cuanto a las estrategias de integración de las firmas se configurarán los tipos de inversión que se realizarán, bien sea en una estructura vertical - añadir una etapa al proceso productivo ya sea antes o después de la actividad final de la empresa - u horizontal - producción de la misma línea general de bienes como los producidos en la economía de la firma inversora-.

En los modelos de integración vertical la producción que da origen a la IED se encuentra separada en diversos países y economías debido a la existencia de diferentes dotaciones de factores en las diversas localizaciones de la cadena productiva - Helpman y Krugman (1985) -. La decisión de invertir en el exterior es explicada por la necesidad de la empresa de acceder a factores de bajo costo en algunas economías extranjeras. Entonces, la consecuencia lógica es que las firmas separarán su producción en diferentes segmentos o etapas, ubicando cada etapa en la localidad internacional de menor 
coste e intercambiando insumos intermedios y componentes entre las distintas ramas. Este tipo de integración expone en gran medida el origen de los flujos intraindustriales y del comercio intrafirma, al producirse importaciones de partes y piezas o insumos intermedios de las filiales desde sus casas matrices u otras filiales con mayor autonomía y desarrollo.

Los modelos de integración horizontal explican la presencia de la IED a partir de la manifestación de firmas que poseen varias plantas de producción en diferentes países, reproduciendo bajo distintas intensidades la planta matriz. Markusen y Venables (1996) indican que las firmas apreciarán la proximidad de los demandantes al momento de decidir internacionalizarse. De acuerdo con la "hipótesis de proximidad-concentración" desarrollada y formalizada por Brainard, las estructuras industriales horizontales prevalecerán cuando más elevados sean los costos de transporte y cuando: las barreras arancelarias y de inversión sean bajas. Además, lo anterior se complementaría si el porcentaje de gasto en economías de escala en la planta filial sea bajo con relación a las economías de escala en el ámbito corporativo. Así es que las estrategias de la búsqueda de mercados dan lugar a este tipo de filiales, con excepción de las actividades de I\&D, que tienden a centralizarse en el origen geográfico de sus capacidades tecnológicas.

La combinación de las estrategias mencionadas es denominada como estrategia compleja. La UNCTAD (2001) indica que las ET han empezado a transformar a sus filiales en parte integrante de las redes de distribución y producción, las que a su vez se integran regional y globalmente; que van ajustando de acuerdo a la coyuntura entre las diversas economías donde se localizan. Como se puede distinguir, se enfatiza en los determinantes de la localización, ya que para el caso del presente estudio, especialmente en la sección econométrica, resulta una herramienta útil para analizar los procesos de la IED en su focalización en gran parte de Latinoamérica.

\section{Inversión Extranjera Directa recibida por diecinueve países de Latinoamérica}

A partir de la década de los noventa, las reformas liberales y la estabilidad macroeconómica mejoraron significativamente la percepción de los inversores extranjeros, a pesar de los problemas 
financieros que afectaron a la región ${ }^{8}$. Pese a todo, la coyuntura de la liberalización de los mercados enmarcaba las nuevas oportunidades suscitadas, principalmente por la privatización de las empresas públicas, la ola de fusiones y las concesiones otorgadas por los gobiernos latinoamericanos a firmas extranjeras. Esto viabilizó una importante entrada de IED y obligó subsecuentes inversiones para modernizar y expandir las empresas que cambiaron de propiedad. Las adquisiciones bien pueden relacionarse a las privatizaciones del sector público, pero las fusiones son relacionadas con el sector privado. Con la profundización de las reformas económicas, muchos propietarios de empresas latinoamericanas se habrían obligado a vender o fusionar sus empresas. De hecho, una parte importante de estas empresas que después se fusionaron, pertenecían a conglomerados económicos diversificados, que para subsistir debían asociarse, ante la inminente competencia de los líderes mundiales BID-IRELA 1998-. En lo que respecta a la IED recibida por los diecinueve países de estudio, cabe recalcar que en suma fueron los más destacados en toda Latinoamérica'. Esta afirmación es confirmada por varias fuentes, que a su vez pueden facilitar el estudio comparativo de la IED en Latinoamérica. No obstante, los datos no necesariamente son los mismos. Esto demuestra que aún no se han homogenizado los criterios de la medición de los flujos de IED mundiales ${ }^{10}$. De todas maneras, las diferencias pueden considerarse poco significativas, ya que las tendencias no son disímiles.

${ }^{8}$ Como la crisis: mexicana a finales de 1994, asiática en 1997, brasilera 2000 y la argentina en el 2001.

${ }^{9} \mathrm{Su}$ importancia se fundamenta en que se encuentran todos los países de Latinoamérica con excepción de Cuba y Puerto Rico.

${ }^{10}$ De acuerdo a la quinta edición del manual de Balanza de Pagos del Fondo Monetario Internacional, la IED recibida es contabilizada como la adquisición duradera del control de al menos el 10\% de una empresa que se encuentra operando en una economía extranjera. Se considera IED: la compra de patrimonio, reinversión de utilidades y la partida de la cuenta de "otros" de la Balanza de Pagos que incluye capital de largo y corto plazo. 
Gráfico 1. IED recibida por los diecinueve países latinoamericanos por fuente 1990 - 2003 (Millones de US\$)

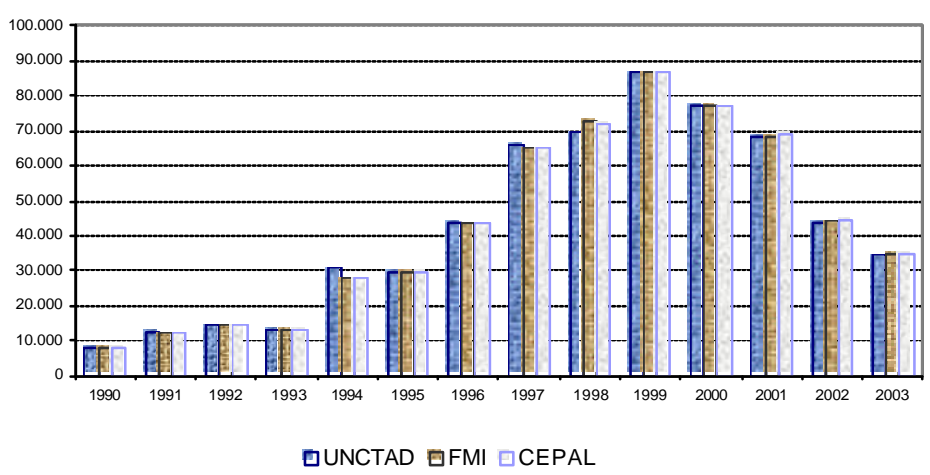

Fuente: Elaboración propia en base a los datos UNCTAD(2004)

El Gráfico $\mathrm{N}^{\mathrm{o}} 1$ indica que el cenit de la atracción de la IED en estos países se produjo entre los años 1998 al 2000, para después disminuir; y situarse en el año 2003 a un poco más de lo recibido en 1995. Esta situación no sólo habría afectado a Latinoamérica sino al resto del mundo, debido al menor ritmo de la actividad económica mundial. Lo que obligó a las ET a una mayor competencia en mercados más reducidos UNCTAD (2004).Asimismo, entre los años 1990 al 2003, los diecinueve países de estudio recibieron un total de 598,584 millones de dólares, de los cuales el 70.6\% se distribuyó entre Brasil, México y Argentina, los países con mayor PIB de la región. En contraste, países como Haití, Honduras y Paraguay fueron los que recibieron, en conjunto, el $0.5 \%$ de la IED total. También, es interesante comprobar que menos del $10 \%$ de la inversión extranjera corresponda a doce países, que incluye a todas las economías de Centroamérica-Caribe y a Ecuador, Bolivia, Paraguay y Uruguay, como puede verse en la Tabla $N^{\circ} 1$. 


\begin{tabular}{|c|c|c|c|c|c|c|c|}
\hline \multicolumn{8}{|c|}{$\begin{array}{r}\text { Tabla } \mathrm{N}^{\circ} 1-\text { FLUJOS DE INVERSIONES EXTRANJERA } \\
\text { RECIBIDAS } \\
\text { (En orden descendente) (Millones de US) }\end{array}$} \\
\hline País & 90-94* & 95-99* & 2000 & 2001 & 2002 & 2003 & Total \\
\hline Brasil & 7593 & 91624 & 32779 & 22457 & 16590 & 10144 & 181187 \\
\hline México & 31241 & 59407 & 16586 & 26776 & 14745 & 10783 & 159537 \\
\hline Argentina & 15134 & 52997 & 10418 & 2166 & 785 & 478 & 81978 \\
\hline Chile & 6036 & 26431 & 4860 & 4200 & 1888 & 2982 & 46397 \\
\hline Venezuela & 4181 & 17245 & 4701 & 3683 & 779 & 2531 & 33120 \\
\hline Colombia & 4091 & 13979 & 2395 & 2525 & 2115 & 1762 & 26867 \\
\hline Perú & 4005 & 11751 & 810 & 1144 & 2156 & 1377 & 21243 \\
\hline Ecuador & 1527 & 3194 & 720 & 1330 & 1275 & 1555 & 9601 \\
\hline Bolivia & 572 & 3689 & 822 & 832 & 1044 & 160 & 7119 \\
\hline Rep Dominicana & 854 & 2969 & 953 & 1079 & 917 & 310 & 7081 \\
\hline Panamá & 960 & 3886 & 603 & 405 & 78 & 792 & 6723 \\
\hline Costa Rica & 1111 & 2402 & 409 & 454 & 662 & 587 & 5624 \\
\hline Guatemala & 451 & 1064 & 230 & 456 & 110 & 104 & 2415 \\
\hline El Salvador & 61 & 1412 & 173 & 279 & 208 & 157 & 2290 \\
\hline Uruguay & 341 & 819 & 273 & 320 & 175 & 263 & 2192 \\
\hline Nicaragua & 165 & 840 & 267 & 150 & 204 & 201 & 1827 \\
\hline Honduras & 237 & 630 & 282 & 193 & 176 & 198 & 1715 \\
\hline Paraguay & 461 & 925 & 104 & 85 & 11 & 82 & 1667 \\
\hline Haití & 15 & 47 & 13 & 4 & 6 & 8 & 93 \\
\hline
\end{tabular}

En resumen, la orientación de la IED a Latinoamérica se dirige ostensiblemente a determinados países de la región, denotando el efecto concentración de la IED. Esto no es más que un efecto de las características propias de la inversión extranjera que se reproducen en el mundo, cuando se concentra en determinados países y zonas geográficas. Además, este comportamiento obedece, ciertamente, al tamaño de mercado relacionado con la potencial riqueza de los países. Por tanto, la evidencia indicaría que las inversiones se concentrarán cuando los mercados se encuentren igualmente 
centralizados. Situación que será aún mayor si la incertidumbre es grande en la periferia.

En cuanto al tipo sectorial de IED que recibe Latinoamérica, esta se ha dirigido a heterogéneas actividades empresariales, desde: turismo, finanzas, energía, minería, servicios básicos, telecomunicaciones, industria manufacturera, etc. Es posible afirmar que en casi en la mayoría de los países latinoamericanos, la IED se ha encaminado a los tres sectores, Servicios, Manufacturas explotación Primaria. Sin embargo, en algunas de estas economías la presencia de estas inversiones ha tendido, expresamente, a determinado sector.

Por consiguiente, a pesar de las limitaciones de información, se ha logrado reunir los Country Profiles que elabora la UNCTAD de los países latinoamericanos en cuestión, para extraer de los mismos la información de la inversión extranjera sectorial. Para evitar la pérdida de información se ha determinado discriminar la IED conforme a los tres sectores económicos ya citados. Cabe recalcar que la información sectorial de Guatemala, Haití y Paraguay no existía. También en muchos de los casos no se disponían de todas las series completas entre los años 1990 a 2003.

Pese a todo, la falta de datos no invalida los resultados presentes en la Tabla 2. Se destaca el hecho de que la orientación sectorial de la IED se inclina hacia el sector servicios. La supremacía de este sector se evidencia en 11 de los 16 países: Argentina, Brasil, Chile, Colombia, El Salvador, Honduras, Nicaragua, Paraguay, Perú, República Dominicana y Uruguay. El sector manufacturero sólo es superior en Costa Rica y México, y por último, el sector primario es más importante en Bolivia, Ecuador y Venezuela. Además, llama la atención la importancia relativa de las estadísticas no identificadas ${ }^{11}$.

Como se puede apreciar, en Argentina, Bolivia y México las conclusiones de las tendencias de focalización pueden presentar dudas y hasta pueden parecer contradictorias. Sin embargo, son fácilmente esclarecidas, si se resta importancia a algunas entradas únicas de IED: en Argentina, la privatización de la empresa petrolera estatal Argentina por 13439 millones de dólares, en Bolivia, la privatización de la Empresa estatal de Telecomunicaciones por más

${ }^{11}$ Conforme a las fuentes consultadas, este componente es definido como tal desde los organismos nacionales que registran los flujos de IED. 
de 600 millones de dólares y en México, la venta del BANAMEX por más de 12500 millones de dólares. Es indudable que estas operaciones sesgan la orientación sectorial de las inversiones en estos países.

Tabla 2. Inversión extranjera directa por sectores en Latinoamérica, 1992-2002

\begin{tabular}{|l|c|c|c|c|c|}
\hline Países & Periodo & Primario & $\begin{array}{c}\text { Manufac- } \\
\text { turas }\end{array}$ & Servicios & $\begin{array}{c}\text { No } \\
\text { especi- } \\
\text { ficado }\end{array}$ \\
\hline Argentina & $92-02$ & $37 \%$ & $22 \%$ & $34 \%$ & $7 \%$ \\
\hline Bolivia & $90-02$ & $44 \%$ & $12 \%$ & $44 \%$ & $0 \%$ \\
\hline Brasil & $96-02$ & $3 \%$ & $21 \%$ & $67 \%$ & $9 \%$ \\
\hline Chile & $92-02$ & $34 \%$ & $12 \%$ & $55 \%$ & $0 \%$ \\
\hline Colombia & $94-02$ & $17 \%$ & $21 \%$ & $62 \%$ & $0 \%$ \\
\hline Costa Rica & $92-02$ & $9 \%$ & $61 \%$ & $29 \%$ & $1 \%$ \\
\hline Ecuador & $92-02$ & $82 \%$ & $6 \%$ & $12 \%$ & $0 \%$ \\
\hline El Salvador & $98-02$ & $3 \%$ & $18 \%$ & $80 \%$ & $0 \%$ \\
\hline Honduras & $93-02$ & $19 \%$ & $32 \%$ & $47 \%$ & $2 \%$ \\
\hline México & $94-02$ & $1 \%$ & $44 \%$ & $44 \%$ & $11 \%$ \\
\hline Nicaragua & $92-00$ & $17 \%$ & $10 \%$ & $73 \%$ & $0 \%$ \\
\hline Paraguay & $90-01$ & $11 \%$ & $35 \%$ & $54 \%$ & $0 \%$ \\
\hline Perú & $92-02$ & $12 \%$ & $13 \%$ & $75 \%$ & $12 \%$ \\
\hline $\begin{array}{l}\text { Rep. } \\
\text { Dominicana }\end{array}$ & $95-02$ & $0 \%$ & $3 \%$ & $93 \%$ & $3 \%$ \\
\hline Uruguay & $01-02$ & $26 \%$ & $11 \%$ & $65 \%$ & $-2 \%$ \\
\hline Venezuela & $90-02$ & $44 \%$ & $5 \%$ & $16 \%$ & $36 \%$ \\
\hline
\end{tabular}

La tendencia general de la focalización de la IED es a concentrarse en el sector servicios, con las siguientes excepciones: sector primario en Bolivia, Ecuador y Venezuela y el sector manufacturero en Costa Rica y México.

Con el propósito de hacer más preciso el análisis arriba señalado, en el Gráfico $\mathrm{N}^{\mathrm{o}} 3$ es posible observar la evolución sectorializada de la IED agregada de 12 países latinoamericanos. En esta exposición, no se toman en cuenta a: El Salvador, Guatemala, Haití, Panamá, Paraguay y Uruguay por la falta o insuficiencia informativa. Se 
toman en consideración los años comprendidos entre 1996 al 2002, por coincidir en este espacio temporal la mayoría de la serie de datos.

Gráfico N N 3 - Importancia de los Sectores Económicos en la Atracción de la IED 1996 - 2002

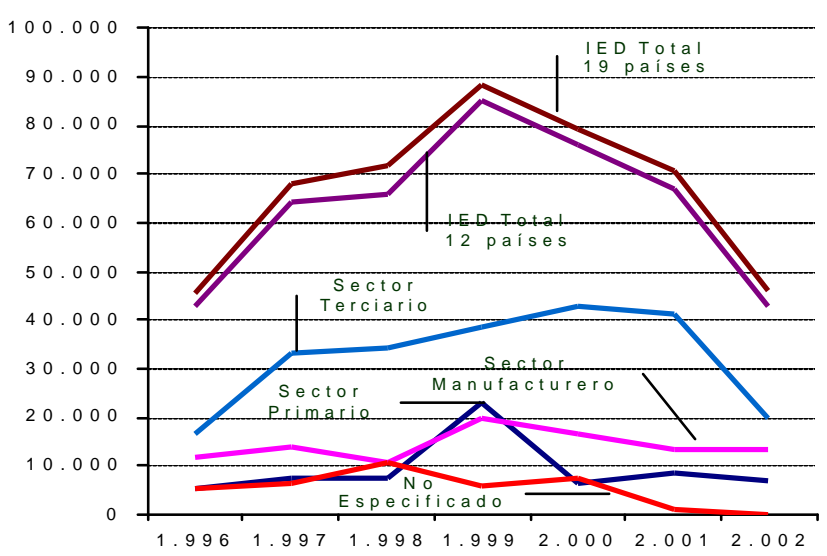

Elaboración propia a partir de varios números de los informes Country Profiles UNCTAD

En síntesis, la inversión extranjera en el sector servicios vista de una forma agregada y/o por país, tiene una importancia casi absoluta en las propensiones inversoras sobre el resto de los sectores económicos. En el anexo se incluye una comparación entre países.

\section{Factores determinantes de la Inversión Extranjera Directa}

Antes de proceder a exponer las relaciones entre la IED y sus potenciales variables explicativas, conviene detallar, en el Cuadro 1, las especificaciones que se han realizado en diversos análisis sobre el tema. Complementando el Cuadro $\mathrm{N}^{\mathrm{o}} 1$, muchos estudios con el propósito de obtener mayor robustez explicativa, han procurado trabajar con flujos de IED bilateral, para grupos de países receptores. Estudios de estas características han sido elaborados por Morsink (1998), Martin Velásquez (2000), Carstensen y Toubal (2003). Otras investigaciones, además de tomar en cuenta lo anterior, han discriminado a los sectores y actividades empresariales a donde se enfocan los flujos de IED, como lo ejemplifican Carr, Markusen 
Maskus (1998), Resmini (1999), Gao (2000) Altomonte y Guagliano (2001). Numerosos de estos trabajos se han centrado en los países Centroeuropeos y del Sudeste Asiático. En menor medida se han realizado en Latinoamérica, debido a la carencia de información normalizada bajo criterios homogéneos.

Los estudios latinoamericanos que se aproximan a las características mencionadas se ciernen a la información que otorga la OECD y solo engloban a algunos países y regiones de Latinoamérica como los siguientes: Artal, Fernández y Domingo (2001) en el MERCOSUR, Artal (2002), Bittencourt y Domingo (2002) en Argentina, Costa (2002) en Brasil, Ramirez (2002) en México. Todos concluyen que el principal determinante de los flujos de IED es el tamaño de mercado de los países receptores. Entretanto, el efecto del resto de las variables causales presenta distintas matizaciones que resultan concordantes con las estructuras productivas y sectores que motivan la inversión extranjera en los países.

Cuadro $N^{o} 1$ - Principales variables utilizadas en estudios empíricos sobre los factores determinantes de la IED

\begin{tabular}{|l|c|l|}
\hline Variables dependientes & \multicolumn{2}{|c|}{ Variables independientes } \\
\hline \multirow{4}{*}{ - IED enviada } & $\begin{array}{c}\text { Tamaño de } \\
\text { mercado }\end{array}$ & $\begin{array}{l}\text { - Economías de escala } \\
\text { - IED recibida } \\
\text { - Población }\end{array}$ \\
\cline { 2 - 3 } - Coeficiente & Riesgo & $\begin{array}{l}\text { - Riesgo político } \\
\text { - Solvencia económica del país } \\
\text { receptor }\end{array}$ \\
\cline { 2 - 3 } $\begin{array}{l}\text { IED/PIB } \\
\text { - Coeficiente }\end{array}$ & Apertura \\
IED/(IED+ & $\begin{array}{l}\text { - Exportaciones } \\
\text { Inversión interna) }\end{array}$ & $\begin{array}{l}\text { Importaciones } \\
\text { - Grado de apertura comercial } \\
\text { (X+M)/PIB }\end{array}$ \\
\cline { 2 - 3 } & Costes laborales & $\begin{array}{l}\text { - Coste promedio de los } \\
\text { trabajadores } \\
\text { - Proporción del trabajo } \\
\text { calificado sobre el total }\end{array}$ \\
\hline
\end{tabular}




\begin{tabular}{|c|c|c|}
\hline $\begin{array}{l}\text { - Coeficiente IED/ } \\
\text { inversión interna } \\
\text { - Exportaciones } \\
\text { X/(X+producción }\end{array}$ & $\begin{array}{l}\text { Estabilidad } \\
\text { macroeconómica }\end{array}$ & $\begin{array}{l}\text { - Crecimiento del producto } \\
\text { - Volatilidad del tipo de cambio } \\
\text { - Inflación } \\
\text { - Grado de ahorro interno } \\
\text { - Tipo de cambio } \\
\end{array}$ \\
\hline $\begin{array}{l}\text { extranjera) } \\
\text { - Coeficiente IED/ }\end{array}$ & $\begin{array}{l}\text { Políticas } \\
\text { comerciales }\end{array}$ & $\begin{array}{l}\text { - Nivel de protección arancelaria } \\
\text { - Tasa de los impuestos } \\
\text { corporativos }\end{array}$ \\
\hline $\begin{array}{l}\text { FBKF } \\
\text { - Producción } \\
\text { extranjera / } \\
\text { producción } \\
\text { interna }\end{array}$ & $\begin{array}{c}\text { Intensidad y } \\
\text { disponibilidad de } \\
\text { factores } \\
\text { productivos }\end{array}$ & $\begin{array}{l}\text { - Intensidad de investigación y } \\
\text { desarrollo } \\
\text { - Intensidad de gastos de } \\
\text { publicidad } \\
\text { - Disponibilidad de recursos } \\
\text { naturales } \\
\text { - Presencia de mano de obra } \\
\text { cualificada }\end{array}$ \\
\hline $\begin{array}{l}\text { - Producción de } \\
\text { las filiales }\end{array}$ & $\begin{array}{l}\text { Otras ventajas } \\
\text { comparativas }\end{array}$ & $\begin{array}{l}\text { - Proximidad con los países de } \\
\text { origen de la inversión } \\
\text { - Costos de transporte } \\
\text { - Grado de concentración } \\
\text { industrial } \\
\text { - Existencia de costos } \\
\text { sumergidos }\end{array}$ \\
\hline
\end{tabular}

\subsection{Análisis Econométrico}

Una vez realizado el diagnóstico de la información disponible, el presente análisis econométrico se encuentra circunscrito a la explicación de la IED en diecinueve países latinoamericanos, desde una óptica global y regional, con una posibilidad restringida de exponer la IED sectorial. Se identifican tres variables dependientes de IED: global $^{12}$, de servicios ${ }^{13}$, de manufacturas y de explotación

\footnotetext{
${ }^{12}$ Todos los países enumerados en la Tabla $\mathrm{N}^{\mathrm{o}} 1$

${ }^{13}$ Para los modelos de la IED en servicios y manufacturas se toman en cuenta a los mismos países: Argentina, Bolivia, Brasil, Chile, Colombia, Costa Rica, Ecuador, Honduras, México, Perú, Venezuela.
} 
primaria $^{14}$. También, se reconocen tres modelos subregionales: Comunidad Andina ${ }^{15}$, MERCOSUR-Chile ${ }^{16}$ y el conjunto de países Centroamericanos-Caribeños y México $^{17}$. El espacio temporal pretendido en esta investigación abarca los años comprendidos entre 1990 y 2003. En este sentido, se ha procurado mantener dichos márgenes, temporales, en los modelos econométricos. No obstante, la cobertura periódica se ha visto recortada en algunos casos por la falta o inexistencia de algunas variables u observaciones.

La técnica utilizada en la modelación econométrica es la de panel, por las características de las bases de datos y las ventajas homogenizadoras que implican los resultados de los mismos en las interpretaciones económicas. A los modelos señalados se han aplicado el test $\mathrm{F}$ de estabilidad de parámetros, aceptándose la homogeneidad en los coeficientes angulares en todos los modelos. También, se han realizado análisis de varianza test LM -Lagrange-, los cuales indican la existencia de heterocedasticidad; por lo que la estimación definitiva se ha realizado conforme a la técnica de Mínimos Cuadrados Generalizados (MCG), método que asume la heterocedasticidad en los datos de panel. Se ha contrastado la homogeneidad en los coeficientes angulares, es decir, los parámetros de las variables explicativas; con excepción de la constante, ejercen un impacto uniforme en todos los modelos. Por consiguiente, en el Cuadro 2 es posible apreciar las variables ensayadas en los respectivos modelos.

Todas las estimaciones econométricas, con la salvedad de los modelos sectoriales en manufacturas y en explotación primaria, generaron modelos coherentes con los requisitos necesarios para obtener estimadores óptimos.

\footnotetext{
14 Para el modelo de la IED en de explotación primaria se consideran a los mismos países de los otros sectores con excepción de Costa Rica y México. Se desestima a México y Costa Rica por la poca relevancia de este sector en la atracción de IED.

${ }^{15}$ Bolivia, Colombia, Ecuador, Perú y Venezuela.

${ }^{16}$ Argentina, Brasil, Chile, Paraguay y Uruguay.

17 Costa Rica, El Salvador, Guatemala, Honduras, México, Panamá y República Dominicana. Se desestiman a Nicaragua y Haití, porque sus respectivas evoluciones de IED no tienen aspectos homogéneos con el resto de los países.
} 


\begin{tabular}{|c|c|c|c|c|}
\hline \multicolumn{5}{|c|}{ Cuadro 2 - Determinantes de la IED en latinoamérica ${ }^{18}$} \\
\hline $\begin{array}{l}\text { Determinantes } \\
\text { de la IED }\end{array}$ & $\begin{array}{c}\text { Sigla de } \\
\text { las } \\
\text { Variables } \\
\end{array}$ & Variables & Unidades & $\begin{array}{l}\text { Signos } \\
\text { Esperados }\end{array}$ \\
\hline \multirow[b]{2}{*}{$\begin{array}{l}\text { Tamaño de } \\
\text { mercado }\end{array}$} & POB & Población & Millones & $(+)$ \\
\hline & PIB & \begin{tabular}{|l} 
Producto Interno \\
Bruto
\end{tabular} & $\begin{array}{c}\text { Millones de } \\
\text { US\$ }\end{array}$ & $(+)$ \\
\hline \multirow{5}{*}{$\begin{array}{l}\text { Apertura } \\
\text { Comercial }\end{array}$} & $\mathrm{XM}$ & \begin{tabular}{|l|} 
Exportaciones mas \\
Importaciones
\end{tabular} & $\begin{array}{c}\text { Millones de } \\
\text { US\$ }\end{array}$ & $(+)$ \\
\hline & M & Importaciones & $\begin{array}{c}\text { Millones de } \\
\text { US\$ }\end{array}$ & $(+)$ \\
\hline & MK & $\begin{array}{l}\text { Importación de } \\
\text { bienes de capital }\end{array}$ & $\begin{array}{c}\text { Millones de } \\
\text { US\$ }\end{array}$ & $(+)$ \\
\hline & $\mathrm{XP}$ & $\begin{array}{l}\text { Exportaciones } \\
\text { primarias* }\end{array}$ & $\begin{array}{c}\text { Millones de } \\
\text { US\$ }\end{array}$ & $(+)$ \\
\hline & $\mathrm{XS}$ & $\begin{array}{l}\text { Exportaciones de } \\
\text { manufacturas } * *\end{array}$ & $\begin{array}{c}\text { Millones de } \\
\text { US\$ }\end{array}$ & $(+)$ \\
\hline \multirow[b]{2}{*}{ Riesgo País } & $\mathrm{DP}(-1)$ & $\begin{array}{l}\text { Derechos Políticos } \\
\text { rezagados un } \\
\text { periodo }\end{array}$ & Puntuación & $(-)$ \\
\hline & $\operatorname{PR}(-1)$ & $\begin{array}{l}\text { Respeto a la } \\
\text { propiedad privada } \\
\text { rezagado un } \\
\text { periodo }\end{array}$ & Puntuación & $(-)$ \\
\hline Costes Laborales & SL & Salarios & US\$ & $(-) \circ(+)$ \\
\hline Dummies & D97, D99 & $\begin{array}{l}\text { Privatizaciones y } \\
\text { entradas atípicas de } \\
\text { inversión }{ }^{19}\end{array}$ & ----- & $(+)$ \\
\hline $\begin{array}{l}\text { Estabilidad } \\
\text { Macroeconómica }\end{array}$ & $\mathrm{TC}$ & Tipo de cambio & $\begin{array}{c}\text { US\$ / } \\
\text { Moneda } \\
\text { Local } \\
\end{array}$ & $(-)$ \\
\hline
\end{tabular}

${ }^{18}$ Relacionado con las probables variables explicativas, se puede advertir que se han omitido las variables que reflejen proporciones, por ejemplo: el índice de apertura comercial $(\mathrm{X}+\mathrm{M})$ / PIB., ya que Los efectos netos de este tipo de índice pueden no ser claros.

19 D97 Colombia y Venezuela, D99 Argentina, Brasil, Chile, El Salvador, Haití, Nicaragua y República Dominicana. 
En los resultados se observa que los factores determinantes de la IED en los países estudiados son los siguientes:

El tamaño de mercado representa diversos grados de conglomeración de riqueza, que condiciona los flujos de inversión extranjera. Los países que ostenten mayores grados de producción interna, ya sea producto de su desarrollo económico o de una elevada población, tendrán mayores probabilidades de recibir inversión extranjera. En este sentido, será más fácil para las firmas inversoras generar economías de escala y aprovechar de las ventajas que brindan sistemas económicos que permiten la libre movilidad de factores de producción. Nótese en el Cuadro $\mathrm{N}^{\mathrm{o}} 3$, que el tamaño de mercado, además del modelo Global, sólo es manifiestamente importante en los modelos MERCOSUR-Chile y en la IED del sector servicios. El MERCOSUR-Chile habría representado el ejemplo de incisividad de las ET de localizarse en la subregión, para aprovechar un mercado interno de más de 220 millones de habitantes, con un poder adquisitivo progresivo, gracias a las auspiciosas expectativas de crecimiento que imperaban en la década de los noventa, a pesar de las crisis financieras que obstaculizaron la dinámica económica de esta región. El efecto conjunto de estos hechos derivó en una recesión económica, deteriorando los niveles de consumo, ocasionando inclusive desinversiones que afectaron a la Argentina. Las estrategias que habían perseguido las ET se ajustaban al tipo de integración horizontal, con el propósito de coordinar las actividades empresariales entre plantas manufactureras, principalmente, automotrices como lo indican Bisang y Gomez (1999). El efecto del tamaño de mercado en la determinación de la IED en el sector servicios es complementario al identificado en el modelo Global, debido a que la orientación principal de la IED en Latinoamérica se ha dirigido a este sector. Las características monopólicas de estas actividades junto al crecimiento explosivo de las actividades empresariales que proporcionaban el uso de las nuevas tecnologías, al alcance de una población con mayores posibilidades de consumo telecomunicaciones e Internet -, configuraron el espectro de oportunidades más importantes para las firmas extranjeras. 


\section{Cuadro $\mathrm{N}^{\mathrm{o}} 3$ - Resultados econométricos}

\begin{tabular}{|c|c|c|c|c|c|c|}
\hline Variable dep. & \multicolumn{2}{|c|}{$\log (\mathrm{I})$} & \multicolumn{2}{|c|}{$\log (\mathrm{IT})$} & $\log (\mathrm{IS})$ & $\log ($ IP) \\
\hline Modelos & \multicolumn{2}{|c|}{$\begin{array}{c}(1) \\
\text { General }\end{array}$} & \multicolumn{2}{|c|}{ IED $\stackrel{(2)}{\text { servicios }}$} & $\begin{array}{c}\text { (7) } \\
\text { IED Manu- } \\
\text { facturas }\end{array}$ & $\begin{array}{c}(8) \\
\text { IED Primario }\end{array}$ \\
\hline Periodo & \multicolumn{2}{|l|}{$96-03$} & \multicolumn{2}{|c|}{$90-99$} & $96-03$ & $90-02$ \\
\hline Métodos & PLS & $\overline{\mathrm{MCG}}$ & PLS & $\overline{\mathrm{MCG}}$ & PLS & PLS \\
\hline $\mathrm{L}(\mathrm{PIB})$ & 0.50 & $0.67 \mathrm{c}$ & - & - & $-0.68^{a}$ & ---- \\
\hline$\overline{\mathrm{L}(\mathrm{POB})}$ & - & - & $4.97 \mathrm{c}$ & $2.97 \mathrm{c}$ & - & ---- \\
\hline $\mathrm{L}(\mathrm{XM})$ & $0.84 \mathrm{c}$ & $0.81 \mathrm{c}$ & - & - & - & - \\
\hline $\mathrm{L}(\mathrm{M})$ & ---- & ---- & $1.18 \mathrm{c}$ & $1.39 \mathrm{c}$ & ---- & ---- \\
\hline $\mathrm{L}(\mathrm{MK})$ & ---- & ---- & ---- & ---- & $1.38^{\mathrm{c}}$ & $1.27^{\mathrm{c}}$ \\
\hline PR (-1) & $-0.49 \mathrm{c}$ & $-0.41 c$ & ---- & ---- & ---- & ---- \\
\hline$\overline{\mathrm{DP}}(-1)$ & ---- & ---- & ---- & ---- & ---- & ---- \\
\hline $\mathrm{L}(\mathrm{SL})$ & 0.42 & ---- & $0.82 *$ & ---- & 0.38 & ---- \\
\hline D97 & $0.71 *$ & $0.65 c$ & $1.64 *$ & $0.73 c$ & $-0.20^{\mathrm{a}}$ & 1.21 \\
\hline D99 & $0.83 c$ & $0.86 c$ & 0.72 & $1.26 \mathrm{c}$ & 0.68 & $1.59 *$ \\
\hline $1(\mathrm{XP})$ & ---- & ---- & ---- & ---- & ---- & $-0.46^{\mathrm{a}}$ \\
\hline $2(\mathrm{XS})$ & ---- & ---- & ---- & ---- & $-0.21^{\mathrm{a}}$ & ---- \\
\hline $3 \mathrm{~L}(\mathrm{TC})$ & ---- & ---- & $\begin{array}{ll}--- \\
\end{array}$ & ---- & -0.08 & $-0.86^{\mathrm{c}}$ \\
\hline $\mathrm{R}^{2}$ ajustado & 0.93 & $\begin{array}{l}0.99 \mathrm{y} \\
0.92^{\text {aa }}\end{array}$ & 0.86 & $\begin{array}{l}0.98 \mathrm{y} \\
0.82^{\text {aa }}\end{array}$ & 0.86 & 0.67 \\
\hline Durbin-Watson & 2.13 & $\begin{array}{l}1.81 \mathrm{y} \\
2,01^{\text {aa }}\end{array}$ & 1.93 & $\begin{array}{c}1.92 \mathrm{y} \\
2.00\end{array}$ & 1.70 & 1.26 \\
\hline $\mathrm{N}^{\mathrm{o}}$ obs. & 148 & 151 & 105 & 113 & 99 & 87 \\
\hline
\end{tabular}

\begin{tabular}{|c|c|c|c|c|c|c|c|c|}
\hline Variable dep & \multicolumn{8}{|c|}{$\log (\mathrm{I})$} \\
\hline Modelos & \multicolumn{2}{|c|}{$\begin{array}{c}\text { (3) } \\
\text { Com. } \\
\text { Andina 1 }\end{array}$} & \multicolumn{2}{|c|}{$\begin{array}{c}\text { (4) } \\
\text { Com. } \\
\text { Andina } 2\end{array}$} & \multicolumn{2}{|c|}{$\begin{array}{c}\text { (5) } \\
\text { Mercosur } \\
\text { y Chile }\end{array}$} & \multicolumn{2}{|c|}{$\begin{array}{c}(6) \\
\text { Centro- } \\
\text { américa, } \\
\text { Caribe y } \\
\text { México }\end{array}$} \\
\hline Periodo & \multicolumn{2}{|c|}{$96-03$} & \multicolumn{2}{|c|}{$96-03$} & \multicolumn{2}{|c|}{$96-03$} & \multicolumn{2}{|c|}{$91-03$} \\
\hline Métodos & PLS & $\mathrm{MCG}$ & PLS & $\overline{\mathrm{MCG}}$ & PLS & MCG & PLS & $\mathrm{MCG}$ \\
\hline $\mathrm{L}(\mathrm{PIB})$ & 0.57 & - & 1.40 & - & 1.17 & $0.97^{\mathrm{c}}$ & $0.15^{\mathrm{a}}$ & - \\
\hline $\mathrm{L}(\mathrm{POB})$ & - & - & - & - & - & - & - & - \\
\hline $\mathrm{L}(\mathrm{XM})$ & - & - & - & - & 0.44 & - & $1.39^{b}$ & $0.99^{c}$ \\
\hline $\mathrm{L}(\mathrm{M})$ & $1.71 \mathrm{c}$ & $1.66 \mathrm{c}$ & $\begin{array}{ll}--- \\
\end{array}$ & $\begin{array}{ll}--- \\
\end{array}$ & $\begin{array}{l}--- \\
\end{array}$ & $\begin{array}{l}--- \\
\end{array}$ & $\begin{array}{ll}--- \\
\end{array}$ & $\begin{array}{ll}--- \\
\end{array}$ \\
\hline L(MK) & ---- & ---- & 0.45 & $0.85 \mathrm{c}$ & ---- & --- & ---- & ---- \\
\hline PR (-1) & $0 . \overline{34 c}$ & $-0.37 c$ & $\begin{array}{c}- \\
0.28 \mathrm{c}\end{array}$ & $-0.19 c$ & $1 . \overline{-} \mathrm{c}$ & $-1.03 c$ & ---- & ---- \\
\hline
\end{tabular}




\begin{tabular}{|l|c|c|c|c|c|c|c|c|}
\hline DP(-1) & ---- & ---- & ---- & ---- & ---- & ---- & -0.17 & $-0.15^{* *}$ \\
\hline L(SL) & -0.68 & ---- & -0.46 & ---- & -0.17 & ---- & 0.44 & ---- \\
\hline D97 & 0.53 & $0.55 \mathrm{c}$ & $0.60 *$ & $0.62 \mathrm{c}$ & ---- & ---- & ---- & ---- \\
\hline D99 & ---- & ---- & ---- & ---- & $0.98 \mathrm{c}$ & $0.87 \mathrm{c}$ & 0.74 & $1.00^{\mathrm{b}}$ \\
\hline $1(\mathrm{XP})$ & ---- & ---- & ---- & ---- & ---- & ---- & ---- & ---- \\
\hline $2(\mathrm{XS})$ & ---- & ---- & ---- & ---- & ---- & ---- & ---- & ---- \\
\hline 3 L(TC) & ---- & ---- & ---- & ---- & ---- & ---- & ---- & ---- \\
\hline $\mathrm{R}^{2}$ ajustado & 0.71 & $\begin{array}{c}0.99 \mathrm{y} \\
0.70^{\text {aa }}\end{array}$ & 0.67 & $\begin{array}{c}0.99 \mathrm{y} \\
0.67^{\text {aa }}\end{array}$ & 0.94 & $\begin{array}{c}0.98 \mathrm{y} \\
0.94^{\text {aa }}\end{array}$ & 0.86 & $\begin{array}{c}0.98 \mathrm{y} \\
0.85^{\text {aa }}\end{array}$ \\
\hline $\begin{array}{c}\text { Durbin- } \\
\text { Watson }\end{array}$ & 2.09 & $\begin{array}{c}1.83 \mathrm{y} \\
1.93^{\text {aa }}\end{array}$ & 1.99 & $\begin{array}{c}1.83 \mathrm{y} \\
1.96^{\text {aa }}\end{array}$ & 2.06 & $\begin{array}{c}1.81 \mathrm{y} \\
2.02^{\text {aa }}\end{array}$ & 1.78 & $\begin{array}{c}1.67 \mathrm{y} \\
1.74^{\text {aa }}\end{array}$ \\
\hline L(PIB) & 40 & 40 & 40 & 40 & 40 & 40 & 77 & 77 \\
\hline
\end{tabular}

NOTA: 1 Logaritmo de Exportaciones de bienes primarios, 2 Logaritmo de Exportaciones de bienes secundarios, 3. Logaritmo del tipo de cambio. c Significación al 1\%, ** Significación al 5\%, *Significación al 10\%, ${ }^{\text {a }}$ No es el signo esperado, ${ }^{\text {aa }}$ Corresponden a los valores estadísticos: con ponderación y sin ponderación.

La apertura comercial es el único factor que afecta la evolución de la IED en todos los modelos estimados con excepción del MERCOSUR. Si bien es cierto que comprende tres variables Agregado de las exportaciones más importaciones, sólo importaciones e importaciones de bienes de capital -, todas se encuentran estrechamente vinculadas para que la IED se materialice. Obsérvese que las exportaciones son sólo tomadas dentro del agregado XM, debido a que los efectos exportadores no tienen una incidencia inmediata en los flujos de inversión como las importaciones. La gran mayoría de los estudios que se ciernen sobre las implicancias comerciales en las inversiones extranjeras, bajo distintos niveles, indican que el comercio tiende a ser complementario, si la estructura industrial es vertical y substitutivo si la organización industrial es horizontal ${ }^{20}$ - estudios en países Clausing (2000), en sectores Pfaffermayr (1996) y en firmas Head y Ries (2001).

Tomando en cuenta lo anterior, los resultados indican que, a nivel Global, en la Comunidad Andina y en los países CentroamericanosCaribeños y México se estuviese dando un efecto complementario de los flujos comerciales con respecto a la localización de la inversión

${ }^{20}$ Aunque como toda afirmación de este tipo tienen sus salvedades. 
extranjera. En contraste, en el MERCOSUR y Chile al observarse que las estrategias de las ET se habrían inclinado hacia estructuras industriales horizontales, habrían producido efectos substitutivos en los flujos comerciales. Este resultado refuerza la importancia del mercado interno de estos países.

En caso de la Comunidad Andina se ha visto por conveniente realizar dos modelos que reproducen casi las mismas conclusiones. La diferencia estriba a que se ha tomado en el primero, las importaciones totales y en el segundo, las importaciones de los bienes de capital. El segundo modelo puede resultar más interesante en las interpretaciones económicas, ya que las importaciones de bienes de capital se encuentran estrechamente supeditadas a los compromisos de inversión de las firmas extranjeras dedicadas a las explotaciones mineras y de hidrocarburos. La relación es evidente, para la explotación de recursos naturales estratégicos se precisan importar bienes de capital, que en general, no producen los países huéspedes.

En cambio, el efecto comercial en la IED localizada en Centroamérica, Caribe y México se centra en la exportación de bienes manufacturados para el mercado Norteamericano. A pesar de la importancia del mercado interno mexicano, a partir de su incorporación en el TLC y tras superar la barrera de exportaciones de los 100000 millones de dólares, este país se ha convertido como el resto de los países del Caribe y Centroamérica, en una rampa exportadora para satisfacer las demandas del mercado más grande del planeta.

El riesgo país es un factor que bien puede representar el marco institucional interno de los países huéspedes. La dinámica entre los actores políticos y sociales son partes importantes en el entramado de variables decisorias que afectan a las firmas para invertir en economías extranjeras. En situaciones en donde, los déficits institucionales que se derivan en desconfianza civil, inestabilidad política, elevada corrupción de funcionarios públicos; ocasionan que cualquier emprendimiento empresarial sea extranjero o nacional se encuentre destinado al fracaso. Lo anterior es demostrado por Smarzynska y Wei (2000) en un análisis sobre los flujos de IED en los países de la Europa Central y del Este. 
Es así que las variables institucionales que resultaron estadísticamente significativas resultaron ser los siguientes índices: Respeto de la Propiedad privada y la Libertad de los Derechos Políticos $^{21}$. Las conclusiones que subyacen en la preeminencia estadística de estos índices son aplastantes. Supone que las firmas inversoras extranjeras pasarían por alto ciertos riesgos asociados a los países considerados conflictivos, siempre y cuando se obtengan beneficios mayores a las opciones alternativas de localización. Implica que las únicas limitaciones del accionar empresarial, con respecto a los niveles institucionales de los países de acogida, lo representan los niveles de garantía que ofrecen los Estados para salvaguardar los derechos de propiedad adquiridos. Este indicador se encuentra rezagado un periodo anual, debido a que los flujos de inversión no reaccionan a la misma velocidad ante los posibles eventos que podrían variar el Respeto de los Derechos de Propiedad.

Por otra parte, este indicador no es tomado en cuenta en la IED del sector servicios por su falta de significación estadística y en el modelo Centroamérica-Caribe y México, porque en esta región el riesgo país tiene una mejor explicación a través del Índice de Liberad de los Derechos Políticos. Puede llamar la atención la aparente contradicción, de todo lo antes citado, si la variable PR(-1) no tiene una presencia significativa en la IED del sector servicios. Este resultado se debe a que se excluyó en la estimación del modelo a muchos países por la falta de observaciones en la variable dependiente, algunos con respetables niveles de riesgo como El Salvador, Guatemala, Haití, Nicaragua, Paraguay y República Dominicana $^{22}$.

${ }^{21}$ Aparte de las variables de riesgo país definidas en el Cuadro $\mathrm{N}^{\circ} 2$, se han probado otros potenciales factores explicativos para los distintos modelos que no resultaron significativos, estos fueron: el Îndice de Libertad Civil de Freedom House, el Índice de Corrupción de Transparencia Internacional y el Índice de Libertad Económica de la Fundación Heritage. Estas medidas de institucionalidad no tuvieron la relevancia estadís tica que proporcionaron los índices: Respeto de la Propiedad privada y la Libertad de los Derechos Políticos.

22 También fueron excluidos Panamá y Uruguay 
En tanto, en el modelo de Centroamérica-Caribe y México el Índice de Liberad de los Derechos Políticos rezagado un periodo, es un factor determinante en la IED localizada en estos países, porque en la década de los noventa finalizaron guerras civiles y las represiones políticas. Las guerras civiles con características totales habrían deteriorado los niveles mínimos de paz para el funcionamiento de la empresa privada y los gobiernos despóticos al desarrollar nuevos círculos de poder habrían proporcionado desfavorables señales a los inversores extranjeros. Este indicador es utilizado frecuentemente en algunos estudios realizados en los países de transición económica; y es empleado como una variable proxy del riesgo económico que implica invertir en una economía extranjera, tal como lo define Hryniuk (2003) en un análisis de la IED en Bielorrusia.

Las dummies capturaron satisfactoriamente en todos los modelos los movimientos atípicos de entrada de IED sucedidos en los años 1997 y 1999. Generalmente estas entradas de inversión extranjera fueron producidas por grandes privatizaciones, fusiones, concesiones e inversiones expansivas que se generaron en la década de los noventa.

Los costes laborables no resultaron estadísticamente significativos en todos los modelos ${ }^{23}$. Muchos de los investigadores que han incorporado esta variable en sus análisis sobre la IED concluyen que: "los costes laborables por sí mismos carecen de la incidencia suficiente para la localización de las inversiones extranjeras en un país particular". Un ejemplo reciente de este tipo de conclusiones las evocan Konnings y Murphy (2003) ante le inquietud de la

\footnotetext{
23 Asimismo, puede que los datos de los costes laborables sean inconsistentes y poco representativos, pr ser medidos conforme a los salarios mínimos nominales en moneda de EEUU - establecidos por ley - y porque no representan cabalmente a los diversos costes salariales de las múltiples actividades económicas donde se desenvuelven las firmas inversoras, con diversos grados de productividad y de intensidades de mano de obra. De todas formas, es una tarea complicada cuantificar los costes salariales de los países sin una generalización, inclusive si sólo tratásemos de un sector o país en especial.
} 
relocalización de las ET de la Europa Occidental, por los bajos salarios de los países del este de Europa.

Por otro lado, en el esfuerzo por interpretar las variables causales del desempeño de la IED en el sector manufacturero y en el de explotación primaria, se ha procurado realizar sus respectivas estimaciones econométricas. Los resultados no proyectaron la consistencia estadística esperada. La existencia de autocorrelación en los residuos y los modestos ajustes de los modelos, hacen presumir que faltan algunas variables explicativas.

\section{Conclusiones}

El principal cuestionamiento que realiza este trabajo son las causas que producen la localización de las firmas inversoras en diecinueve países de Latinoamérica en la década de los noventa y principios del siglo XXI. Como bien se supondrá, el estudio de los determinantes de la IED en este grupo de países tiene sus complicaciones, porque se encuentran en función a razones específicas para cada firma de acuerdo al rubro y actividades que realicen; además de los múltiples factores y condiciones de los países a donde se dirige la inversión. Aunado a lo anterior, la falta de datos homogeneizados de la IED recibida individualizada por país, ha limitado el presente estudio. Por lo tanto, partiendo de la situación mencionada, el presente trabajo ha pretendido hallar los factores determinantes de la IED, conforme al aglutinamiento de las variadas causas y elementos influyentes que propiciaron la inversión extranjera en gran parte de Latinoamérica.

En lo que respecta a la descripción de la IED, se ha logrado recopilar información proporcionada por la UNCTAD y los country profiles anuales sectorializados de dieciséis de los diecinueve países estudiados. Las conclusiones de esta revisión indican que el sector servicios ha sido la actividad más destacada en la recepción de flujos de inversión extranjera. Ciertamente la IED en estas actividades económicas estuvieron favorecidas, porque la mayoría de estas actividades tienen estructuras monopólicas y, asimismo, la coyuntura de la época obligó a los gobiernos latinoamericanos a enajenar a estas empresas, consideradas las más rentables.

También se ha recopilado de los country profiles, la información del origen geográfico de la IED de catorce de diecinueve países latinoamericanos. Los resultados indican que EEUU es el más 
importante inversor en la región, lo que define en cierta medida el grado de intervención que realiza en las economías Latinoamericanas. Además se destaca la progresiva expansión de los países de la Unión Europea. Finalmente, es muy llamativo observar que una importante inversión extranjera provenga de los llamados paraísos fiscales. No es extraño reconocer que los escándalos de corrupción en Latinoamérica se hayan relacionado, usualmente, con los centros financieros.

Seguidamente, se han realizado los ejercicios econométricos. Los resultados obtenidos corroboran que la IED en los diecinueve países latinoamericanos son determinados, principalmente, por el tamaño de mercado, la apertura comercial y el riesgo país, además de sucesos atípicos relacionados a privatizaciones y a grandes emprendimientos empresariales privados. También los resultados confirman que los costes laborables, por sí mismos, no tienen ninguna trascendencia importante en la atracción de la inversión extranjera.

La experiencia empírica de variados análisis efectuados y en diferentes contextos corrobora que la inversión extranjera es demarcada por el tamaño de mercado y la apertura comercial. No obstante, el riesgo país bajo los términos enunciados por este trabajo resulta singular. Concretamente, cuando el riesgo país sintetizado por el índice de respeto a los derechos de la propiedad privada forma parte de los determinantes de la IED.

Por otra parte, con el propósito de complementar y ajustar las interpretaciones del modelo global, se realizan pruebas econométricas especificadas para los tres bloques económicos: Comunidad Andina, MERCOSUR-Chile y los países Centroamericanos - Caribe y México. Bajo este esquema, se puede comprobar que el tamaño de mercado sólo tiene significación en los modelos General y en el MERCOSUR-Chile. En el primer modelo, los resultados concuerdan con lo esperado, ya que desde ese punto de vista es posible advertir el efecto concentración de la inversión extranjera en un grupo de economías de diversas dimensiones. En el segundo modelo, se ratifica la importancia del tamaño de mercado de esta subregión.

Ahora bien, en el modelo Global como se indicaba, el riesgo país cuantificado por el respeto de la propiedad privada es un determinante imprescindible para la atracción de la IED. Vista desde 
una óptica subregional, en los países Centroamericanos - Caribe y México, la variable que mejor explica el riesgo país puede medirse a través del índice de libertad de los derechos políticos. Se concluye que los mejores niveles de institucionalidad, medidos por estos indicadores, corresponden a los países donde se han efectuado importantes entradas de inversión extranjera.

Por otro lado, en los bloques señalados se ha podido contrastar las características particulares de las estrategias empresariales perseguidas por las ET. Las tendencias generales de organización industrial se han manifestado horizontales en los países del MERCOSUR - Chile y en contraste, en la Comunidad Andina y los países Centroamericanos - Caribe y México las tendencias de organización industriales se han inclinado hacia las verticales.

Sobre estos dos últimos bloques es útil reconocer las distintas capacidades de utilización de la dotación de factores y riqueza de estos países. Una parte destacada de las firmas que se han localizado en la Comunidad Andina se ha dirigido a la explotación de recursos naturales estratégicos, debido a que este tipo de industria no precisa de grandes encadenamientos con las economías domésticas por ser, generalmente, intensivas en capital. Por el contrario, en México y los demás países Centroamericanos y el Caribe, las estrategias de las firmas inversoras han combinado la abundancia de mano de obra y la localización cercana con EEUU para establecer factorías manufactureras, con el objeto de abastecer las demandas del mercado norteamericano.

Por otro lado, es posible indicar que los países rezagados en la atracción de IED se presentan una combinación con distintos matices de inestabilidad política, carencia de recursos naturales estratégicos y mercados internos reducidos, como ocurre en Haití. Por último, los resultados econométricos pueden parecer muy condensados, ya que sólo modelan las circunstancias agregadas que determinan a la IED. Es indiscutible que se dejan de lado a muchas de las variables particulares que se encuentran detrás de las manifestaciones agregadas, que indefectiblemente pueden ser influenciadas por políticas públicas y estrategias privadas. Sin duda, el establecimiento o potenciación de observatorios latinoamericanos de los flujos de inversión extranjera es indispensable, para conocer los verdaderos alcances que implican estos movimientos de capital. 


\section{Bibliografía}

Altamonte C., Gugliano C., Competing locations? Market potential and FDI in Central and Eastern Europe vs the Mediterranean, LICOS Centre for Transition Economics, Discussion Paper No 108, 2001.

Artal A., Fernández I., Domingo M., Efectos de la inversión extranjera directa de la OCDE sobre los flujos comerciales de argentina durante los años 90, Jornadas de relaciones económicas entre la Unión Europea y el MERCOSUR, Valencia, 2001.

Artal A., Inversión Extranjera Directa OCDE - Argentina: Un análisis de sus factores comerciales, Tesis Doctoral, Universidad de Valencia 2003.

Banco Mundial, World Development Indicators - CD R., 2003.

Bank Interamerican of Development BID -, Inversión extranjera directa en América Latina, la perspectiva de los principales inversores, Instituto de relaciones Europeas Latinoamericanas IRELA1998

Bisang R. Gómez G., Las inversiones en la industria argentina en la década de los noventa Serie Reformas Económicas $\mathrm{N}^{\circ} 41$ CEPAL, Noviembre 1999..

Bergstrand J., The gravity equation in international trade: some microeconomic foundations and empirical evidence", Review of Economics and Statistics, vol. LXVII, n.3, 1985.

Bittencourt G., Domingo R., Los determinantes de la IED y el impacto del MERCOSUR, El Trimestre Económico Vol. LXXI (1) Num. 281, EneroMarzo 2004, México.

Brainard S., An empirical assessment of the proximity-concentration trade off between multinational sales and trade, The American Economic Review, vol.87, n. 4, 1997.

Brenton P., Di Mauro F., The Potential Magnitude and impact of FDI flows to CEECs, CEPS working document, forthcoming, 1997.

Buckley P. J. y Casson M.C., The Optional Timing of a Foreign Direct Investment in: The Economic Journal, Vol. 91, 1981

Buckley P. J. y Casson M.C. Multinational enterprises in the world economy. Edwurad Elgar, Worcester, 1992

Carr D., Markusen J., Maskus K.,Estimating the knowledge - capital model of the multinational enterprise, NBR, working paper $\mathrm{N}^{\circ} 6773$.

Carstensen K., Toubal F,. Foreign Direct Investment in Central and Eastern European Countries: A Dynamic Panel Analysis, Kiel Institute for World Economics Duesternbrooker Weg 120, Germany, 2003.

CEPAL, Informe, La inversión en América Latina y el Caribe. 1997, 1998, 1999, 2000, 2001, 2002, 2003, 2004

CEPAL, Anuario Estadístico - CD R.2002. 
CEPAL, La inversión extranjera en América Latina y el Caribe, Informe LC/G.2198-P 2002la, Santiago de Chile, 2002.

CEPAL, La competitividad internacional y el desarrollo nacional: implicancias para la política de Inversión Extranjera Directa (IED) en América Latina, Serie 107, Santiago de Chile, 2001.

CEPAL, Anuario Estadístico-CD R., 2003.

Clausing K., Does multinacional activity displace trade?, Economic Inquirí, $\mathrm{N}^{\mathrm{o}} 38 / 2,2000$.

Costa C., Factores de atracción para la inversión extranjera en la economía Brasilera y repercusiones sobre su especialización internacional, Universidad Técnica de Lisboa documento trabajo de CDIN/SEG, 2003.

Dickerson W. Hogue, The Foreign Investment Decisión Making Process, Association for education in internacional business Proceding, 1967.

Dunning J., Trade, location of economic activity and MNE: a search for an eclectic approach, in Ohlin B., Hesselborn P., Wijkman P., (eds.), The international allocation of economic activity, London, MacMillan, 1977.

Dunning J., International production and the multinational enterprise, London, George Allen and Unwin. 1981.

Dunning, J., Re-evaluating the benefits of foreign direct investment, Transnational Corporations, Vol. 3, $\mathrm{N}^{\circ} 1,1994$.

Forte Rosa, The relationship between foreign direct investment and international trade. Substitution or complementarity? A survey, Universidad de Porto, Centro de Estudios de Economía industrial, do trabalho e da empresa CETE, trabalhos em curso n ${ }^{\circ}$ 140, 2004

Gao, T, Ethnic Chinese Networks and International Investment: Evidence from inward FDI in China, Manuscript, University of Missouri, 2000.

Head K., Ries., Overseas investment and firm exports, Review of International Economics $\mathrm{N}^{\circ}$ 9/1,2 001.

Helpman, E. y Paul Krugman, Market Structure and Foreign Trade. Cambridge (Mass), MIT Press. 1985

Hymer Stephen, Empresas multinacionales: la internacionalización del capital, Buenos Aires - Argentina, Ediciones Periferia SRL 1972.

Hryniuk U., What are the main determinants of the FDI inflows in the Belarus?, Thesis of Master of Arts in Economics 2003, National University Kyev-Mohila Academy Ucrania, 2003.

International Monetary Found- International Financial Statistics $C D-R$ September 2004-.

Konings J. Murphy A., Do Multinational Enterprises Relocate Employment to Low Wage Regions? Evidence from European Multinationals, LICOS Centre for Transition Economics, Discussion Paper N ${ }^{\circ}$ 131, 2003. 
Krugman Paul, Geografía y Comercio, Antoni Bosch Editor, Barcelona, 1992

Markusen, James R.y Venables A. J., The Theory of Endowment, Intraindustry, and Multinational Trade, NBER Working Paper 5529, 1996

Martin C, Velázquez F, Determinants of bilateral foreign direct investment flows in the OECD, with a closer look at the former communist countries, European Economy Group, Working paper $\mathrm{N}^{\circ}$ 2/2000.

Morsink R., Foreign Direct Investment and Corporate Networking: A framework for spatial analysis of investment conditions, New Horizons in international business, 1998.

Pfaffermayr, M., Foreign outward direct investment and export en Austrian manufactturing: substitutes or complementary?, Weltwirtschaftliches Archiv, No 132/3., 1996.

Ramirez A; Inversión extranjera en México: Determinantes y pautas de localización, Tesis Doctoral, Universidad Autónoma de Barcelona 2002.

Resmini L., The Determinants of Foreign Direct Investment into the CEECs: New Evidence from Sectoral Patterns Centre for Transition Economics, Katholieke Universiteit Leuven, Discussion Paper 83/1999, Belgium, 1999.

Smarzynska B. y Wei S, Corruption and composition of foreign direct investment: Firm - level evidence, National Bureau of economic research inc, working paper $\mathrm{N}^{\circ} 7969,2000$

United Nations Conference on Trade and Development, UNCTAD, Handbook of statistics 1990, 1995, 2000, 2001, 2002, 2003, 2004.

United Nations Conference on Trade and Development, UNCTAD, World Investment Report, 2000, 2001, 2002, 2003, 2004.

United Nations Conference on Trade and Development, UNCTAD, Country Profiles - Statistics on FDI and the operations of TNCs, Argentina, Brazil, Bolivia, Chile Colombia, Costa Rica, Ecuador, El Salvador, Honduras, Mexico, Nicaragua, Paraguay, Peru, Dominic Republic, Uruguay, Venezuela.

UNCTAD, Informe sobre las inversiones en el Mundo; Las políticas de IED como impulsoras del 2003 desarrollo: Perspectivas nacionales e internacionales, 2003.

www.freedomhause.org

Zhang y Markusen, Vertical Multinationals and Host Country Characteristics, Journal of Development Economics, 1999.

Revista publicada por la Asociación Euro-Americana de Estudios de Desarrollo Económico. http://www.usc.es/economet/aea.htm 


\section{Anexo:}

Comparación relativa entre los países receptores Inversión Extranjera Directa

Es evidente que la IED tiene un peso relativo distinto en los países receptores. Los diferentes tamaños de los mercados interiores, determinados por sus poblaciones y la riqueza que se producen en ellas, configuran la importancia de la inversión extranjera en los respectivos países. El stock de IED es una justa medida de la agregación de los flujos de esta variable. En ella se puede denotar la conjunción de los diversos grados de compromisos e intereses de las firmas inversoras en las economías huéspedes.

De esta manera, llama la atención el caso de México, ya que supera a Brasil en stock de inversión extranjera por más de 37000 millones de dólares, a pesar que Brasil ha sido el más destacado receptor de inversión extranjera entre los años 1990 al 2002. Esto se debe a que México en la década de los ochenta del siglo XX habría sido el más importante receptor de IED en Latinoamérica. No es de extrañar que México recupere su condición de país líder, en estos términos, puesto que en el año 2001 desplazó al Brasil como primera economía de América Latina ${ }^{24}$. Uno de los efectos del empuje económico mexicano se manifiesta a que en el año 2003 los flujos de IED localizados en este país fueron los más altos de Latinoamérica.

\footnotetext{
24 En la década de los noventa, el PIB mexicano siempre se encontró por debajo del brasilero hasta el año 2001. En ese año el PIB mexicano fue de US\$ 618 mil millones y el brasilero de US\$ 503 mil millones. En el año 2003 el PIB brasilero representa tan solo el 79\% del PIB mexicano. Fuente: CD-R International Financial Statistics, September 2004-International Monetary Found
} 
Gráfico A-1.Inversión extranjera total recibida 1990 - 2003. (Millones US\$)

\begin{tabular}{|l|r|}
\hline País & \multicolumn{1}{c|}{$90-03$} \\
\hline Brasil & 181.187 \\
\hline México & 159.537 \\
\hline Argentina & 81.978 \\
\hline Chile & 46.397 \\
\hline Venezuela & 33.120 \\
\hline Colombia & 26.867 \\
\hline Perú & 21.243 \\
\hline $\begin{array}{l}\text { Resto de } \\
\text { Centroamérica* }\end{array}$ & 20.594 \\
\hline Ecuador & 9.601 \\
\hline Bolivia & 7.119 \\
\hline $\begin{array}{l}\text { Rep. } \\
\text { Dominicana }\end{array}$ & 7.081 \\
\hline $\begin{array}{l}\text { Resto } \\
\text { Sudamérica** }\end{array}$ & 3.859 \\
\hline Total & 598.584 \\
\hline
\end{tabular}

1990 - 2003 Flujo de IED $\underline{598676 \text { millones }}$

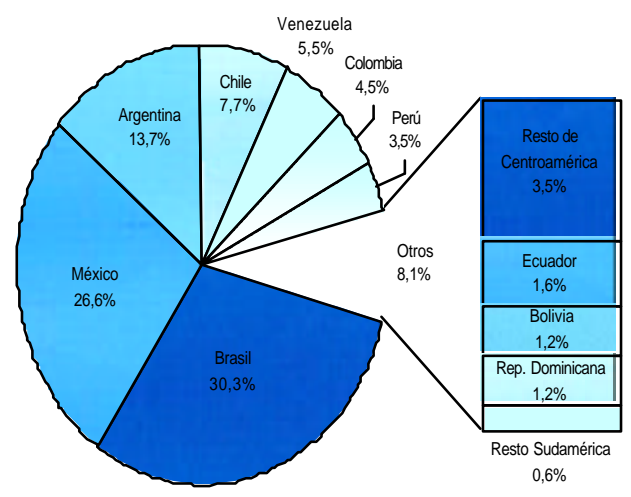

* Panamá, Costa Rica, Guatemala, El Salvador, Nicaragua, Honduras y Haití. ** Paraguay y Uruguay / Elaboración propia a partir de Handbook of estatistics de UNCTAD

Aunque con contextos distintos y con fines explicativos, es posible identificar tres tipos de países. Chile y Panamá ejemplifican aquellas naciones donde coinciden los más altos niveles de stock de IED por habitante y PIB respectivamente, lo que supone que en ambos países la presencia de la propiedad extranjera en sus economías sea de las más importantes en los países estudiados ${ }^{25}$. En contraste, Paraguay y Uruguay pueden encarnar a los Estados donde las menores concesiones a las firmas extranjeras se hayan combinado con las reducidas condiciones de los mercados interiores y la falta de recursos estratégicos para no atraer la inversión extranjera. Por

25 Si bien, se reconozca que Panamá recibe importantes flujos de IED por considerarse al mismo como centro financiero. 
último, Bolivia y Nicaragua representan a los países de menor desarrollo comparativo, pero con los más altos niveles de incidencia extranjera en sus economías. La conjunción de la debilidad económica de este tipo de naciones con una alta presencia de capitales extranjeros que se encuentran concentrados, implica una elevada dependencia en las decisiones empresariales foráneas y un desigual poder de negociación entre sus gobiernos con las firmas extranjeras.

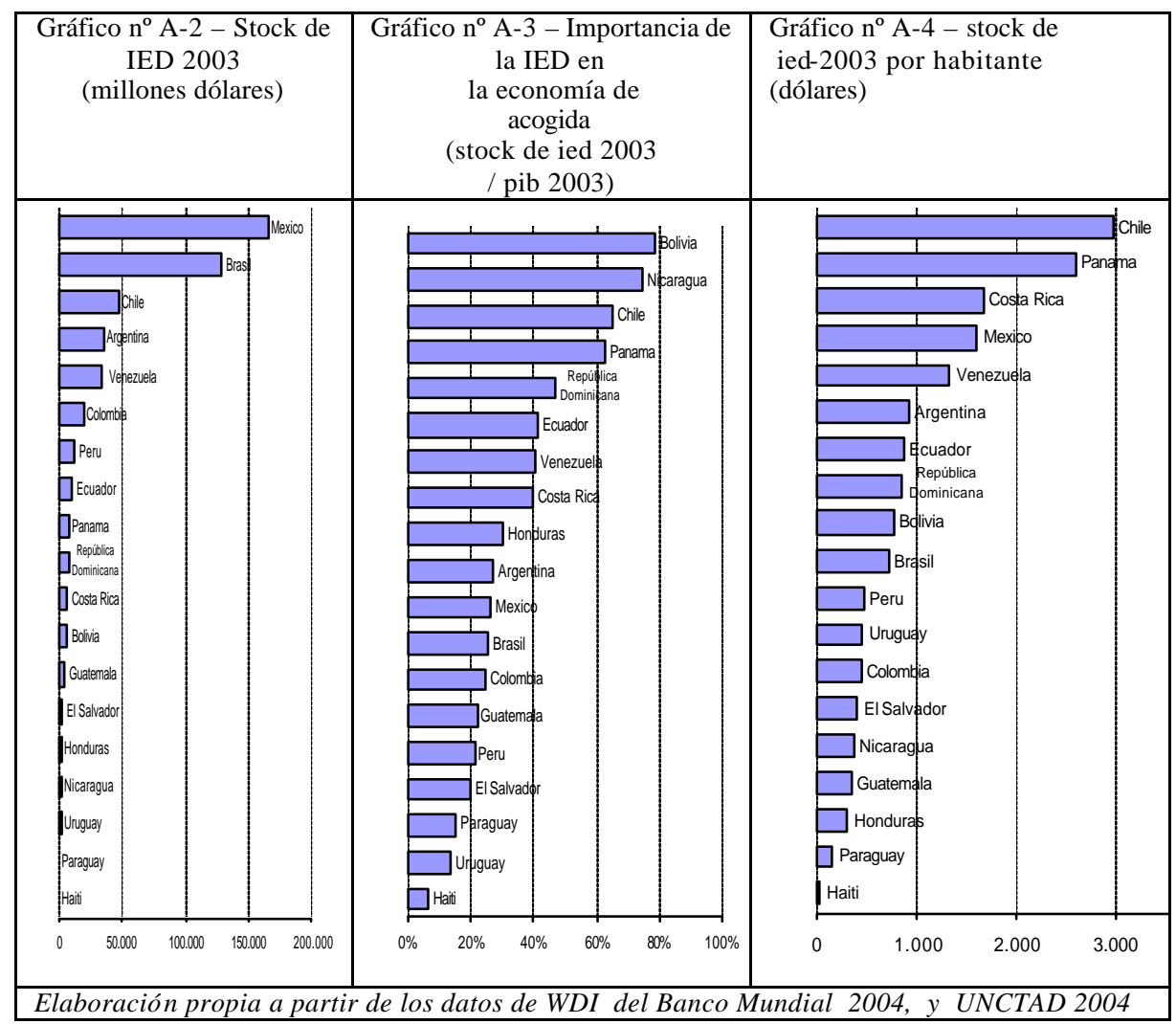

Por otro lado, a un extremo de la lista se encontraría Haití. El stock de IED localizado en este país se encontraría alrededor de los 233 millones de dólares. Este país ilustra el ejemplo utilizado por Zhang y Markusen (1999), al sostener que como condición necesaria para el 
establecimiento de cualquier inversión extranjera en un país, deba existir al menos un nivel mínimo de desarrollo y estabilidad. Finalmente, es posible observar que al margen de los tamaños de mercados, cuando se visualizan las magnitudes relativas, cobran interés analítico otros países de menores dimensiones como los arriba mencionados. La importancia o no de la IED en estas economías, demuestra en los hechos de que existen diversas situaciones de integración en los entornos empresariales internacionales, lo que conlleva a la posibilidad de que, además del tamaño de mercado, existan otros factores determinantes que motiven la inversión extranjera.

\section{Origen geográfico de la Inversión Extranjera Directa}

En el esfuerzo de examinar las influencias de inversión desde la perspectiva de las principales fuentes de IED - es decir, desde los países inversores -, se ha logrado reunir la información referida de catorce de diecinueve países analizados. Las limitaciones de información son análogas a las registradas en la construcción de las series de la inversión extranjera sectorial. En la medida de lo posible, no se ha pretendido suprimir grados de libertad o exclusión de algún país por carecer de información. Los países emisores predominantes y con una presencia en la mayoría de las economías indicadas son: EEUU, España y Holanda. De la misma forma, se observa en menor grado inversiones intrarregionales, siendo los protagonistas de estos flujos Argentina, Chile y Brasil. También destacan las inversiones de los paraísos fiscales, muchas veces asociadas a actividades empresariales de dudosa reputación. En el fondo, el origen geográfico de la IED definiría los distintos parámetros de influencia e intervención de los países emisores en las naciones donde localizan sus inversiones. Los variados cúmulos de intereses, que se formalizan, obligarían a los países emisores a resguardar los emprendimientos, en el extranjero, que tienen cierta gravitación decisoria en sus gobiernos. 